\title{
Construção social da memória em torno a João Baptista Groff e a ilusão biográfica, de Juan Cruz Galigniana ${ }^{1}$
}

Scheyla Tizatto dos Santos ${ }^{2}$

- Enviado em 13/05/2017

- Aprovado em 28/06/2017

As memórias, as personagens e suas histórias, as trajetórias públicas e sua marca em determinada temporalidade são fundamentais para refletir sobre a sociedade e a materialidade dos rastros que as mulheres e os homens produziram e deixaram de suas presenças nas relações públicas, familiares e geracionais. Sob diferentes suportes materiais é possível investigar as histórias de vida em suas dimensões políticas, econômicas e sociais. Suas produções, profissões e os espaços de sociabilidade que frequentam revelam o perfil e as características do sujeito da crítica biográfica, ou ainda, um estudo das obras que se dedicaram a inscrever tal nome na história.

O interesse pelas biografias dos homens e das mulheres públicos é crescente no Brasil nos últimos vinte anos. As estantes das livrarias estão repletas de biografias de artistas, músicos, intelectuais, políticos, porém, nem todas essas obras seguem algum tipo de rigor metodológico ou científico nos termos das ciências humanas. Há biografias de diversificas naturezas, aquelas que são produzidas pelos familiares, por jornalistas e por acadêmicos, todas elas oferecem intencionalidades e interpretações sobre o personagem biografado. Contudo, independente de qual classificação ou tipologia deriva a história de vida publicada, os textos biográficos apresentam um conjunto de documental que auxilia o pesquisador na compreensão da trajetória que deseja conhecer, refletir e as relações que pretende investigar.

\footnotetext{
${ }^{1}$ Dissertação de Mestrado de Juan Cruz Galigniana defendida em 2016 no Programa de Pós-Graduação em Sociologia da UFPR, sob orientação do Prof. Dr. Alexandro Dantas Trindade. A versão completa está disponível no Acervo Digital da UFPR http://acervodigital.ufpr.br/handle/1884/44670.
}

2 Doutoranda vinculada ao Programa de Pós-Graduação em História Cultural da Universidade Federal de Santa Catarina (PPGHistória - UFSC), linha de pesquisa "Sociedade, política e cultura no mundo contemporâneo". Endereço eletrônico: scheyla.tizatto@gmail.com 
O trabalho que Juan Cruz Galigniana produziu durante o mestrado é um exemplo desse interesse e crítica contemporânea das biografias. Na dissertação intitulada "Construção social da memória em torno a João Baptista Groff e a ilusão biográfica", Galigniana subverte a ordem linear de análise de uma história de vida, a qual questiona a partir da perspectiva bourdiana de "ilusão biográfica". Embora, seu objetivo não seja de produzir mais uma biografia sobre a figura pública curitibana, o autor propõe uma crítica as narrativas lineares e heroicizadas que instrumentalizaram as memórias de J.B Groff e do cine-documentário no Estado do Paraná.

A dissertação defendida no Programa de Pós-Graduação em Sociologia da Universidade Federal do Paraná (UFPR), sob orientação do professor Dr. Alexandro Dantas Trindade em 2016, foi organizada em quatro capítulos: (1) "A negociação das imagens na construção social da memória"; (2) "Três esferas narrativas"; (3) "Paranismo e Illustração Paranaense: uma autoimagem para o Paraná nascente"; (4) "A redenção revolucionária". Nestes capítulos Juan Galigniana discutiu como são as construídas as memórias de uma personagem pública como J. B. Groff inserida na busca por uma identidade "paranista" tanto nas imagens que fotografou e filmou, quanto como editor de revista e no trânsito das relações entre os intelectuais curitibanos e paranaenses. Para o autor, analisar a obra, a vida e as relações de J. B. Groff é “alcançar uma abordagem que valide o trabalho sociológico dessa história e relato de vida do personagem" (GALIGNIANA, p. 11, 2016).

No esforço de legitimar sua pesquisa, Juan Cruz Galigniana elaborou questões para o debate acadêmico no campo da sociologia a partir da análise de uma história de vida e das memórias que são construídas por meio dessas trajetórias. O autor lançou mão de um diálogo teórico com Pierre Bourdieu, Daniel Bertaux, Paulo Guérios, Howard Becker e Émile Durkheim, autores que a princípio não são consonantes em múltiplas perspectivas do pensamento social, no entanto, Galigniana explorou desses autores os métodos e as críticas da abordagem biográfica. Nesta incursão, apresentou uma consideração relevante sobre este tipo de manejo intelectual ao destacar que o interesse dos sociólogos não é pelo personagem relatado em si, mas a maneira como esses personagens expressaram e interpretaram a sociedade no contexto que estiveram inseridos. Desse modo, uma biografia ou uma história de vida não é individual, ela é sempre coletiva, pois é uma síntese das relações sociais, das condições políticas e econômicas da temporalidade vivida e dos legados geracionais que repousaram sobre o tempo presente daquele que é biografado.

Ao apresentar um amplo repertório de questões o autor utilizou uma documentação de natureza diversa, entre elas, jornais, revistas, relatórios e entrevistas. Embora, sendo documentação secundária, coletadas principalmente na produção acadêmica sobre J. B. Groff, a dissertação responde ao exercício que 
se propõe, uma vez que produziu uma análise bibliográfica crítica, compondo um rico repositório sobre o tema e um ponto de partida para novas pesquisas. Portanto, nesta investigação, Juan Cruz Galigniana enfatizou as relações sociais dos circuitos intelectuais e políticos de Groff enquanto editor da Revista "Illustração Paranaense", e as condições que o levaram a registrar as imagens da "marcha revolucionária" de 1930. Desse modo, o trabalho apresentou três debates que se relacionam com a construção de uma ideia de Paraná e "Paranismo", são elas: (1) análise das biografias de J. B. Groff, suas lacunas, silêncios e "ilusões biográficas"; (2) o papel da Revista "Illustração Paranaense" na construção do "paranismo"; (3) as condições de produção do cine-documentário "Pátria Redimida".

João Baptista Groff é parte da memória material da cidade de Curitiba, é nome de rua e já foi nome de cinema na cidade. Considerado nas biografias analisadas como o "pioneiro", o "pai" do cinema paranaense, com "vocação" pela abordagem audiovisual como uma marca de sua personalidade desde a infância. Essa narrativa edificante é reproduzida na dissertação com o objetivo de questionar esse tipo de elaboração que o autor chamou de "construção da memória". Galigniana observou que os trabalhos escritos sobre o cine-documentarista paranaense seguiram uma narrativa lógica, coerente e linear. Assim, destacou com aporte de Bourdieu, que nenhuma trajetória segue um esquema determinado e definido, evidenciando as dificuldades em não reproduzir uma "ilusão biográfica". Concluiu, então, que existem métodos que auxiliam o pesquisador na abordagem de trajetórias de vida, entre eles: (1) considerar os circuitos sociais e culturais; (2) analisar as memórias familiares e as obras do autor destacando suas descontinuidades e dificuldades encontradas pelo sujeito da biografia em executar e aplicar os projetos; (3) abordar os contextos e as relações de interdependência ao atribuir valor heurístico tanto a trajetória quanto ao seu entorno.

A partir dos critérios identificados por Galigniana ao abordar os problemas biográficos e seu contexto, a mediação da Revista "Illustração Paranaense" se fez um documento central para alcançar os entornos intelectuais e políticos do projeto de identidade regional que a trajetória de João Batista Groff fez parte. Com essa escala de análise o autor enfatizou com a aproximação de artistas, literatos e agentes de governo a rotinização de práticas, imagens e identificações do Estado do Paraná que representou os códigos simbólicos do "paranismo". Desse modo, os intelectuais desempenharam uma função mediadora entre a construção simbólica e a identificação social regional e nacional, no qual a Revista foi importante meio de difusão e circulação. Para o autor "A Illustração Paranaense teve, portanto, um importante papel local. Era disso que se tratava, de inventar uma identidade, de tentar responder a pergunta sobre "O que é o Paraná?" (GALIGNIANA, p. 75, 2016). 
A trajetória de J. B. Groff se desenrola ao longo do processo de "modernização" da República e, sobretudo, da construção de uma identidade "paranista", sua obra fotográfica e cinematográfica registrou uma arquitetura de cidade no seu cotidiano em transformação. As escolhas técnicas e o olhar de Groff sobre as paisagens foram fundamentais para embasar uma memória de homem extraordinário da história curitibana e do cinema paranaense. Vale destacar que a produção de imagens em formato audiovisual era praticada em Curitiba antes mesmo de J. B. Groff, como por exemplo os trabalhos realizados por Aníbal Requião, este fato levou Galigniana questionar a construção do pioneirismo atribuído ao Groff. Nesta perspectiva o autor levanta algumas hipóteses explicativas, entre elas: (1) a relevância da obra de J. B. Groff em relação ao momento histórico e determinante da vida política da República Brasileira; (2) os registros fotográficos dos símbolos autóctones do Paraná como elementos formação identitária; (3) seu encontro "casual" com o empresário Assis Chateaubriand. Tais horizontes explicativos representaram as escolhas que o autor escolheu quando elaborou sua dissertação.

Ao considerar, portanto, as dimensões interpretativas das memórias construídas em nome de J. B. Groff, é possível demonstrar que essas memórias são construídas em retrospectiva a partir do tempo presente e que toda memória é inventada. A memória de homem extraordinário sobre João Baptista Groff tem como marco definidor os registros de imagem de Getúlio Vargas e das tropas "revolucionária” de 1930. Dessa forma, Galigniana analisou a contingência e as circunstâncias de produção dessas imagens históricas como o cartão de visitas de Groff, o que Ihe abriu as portas como cinegrafista oficial do Departamento Estadual de Imprensa e Propagando (DEIP-PR) durante a gestão do interventor Manoel Ribas (1930-1945). Galigniana descreveu o percurso de João Baptista Groff na busca pelas melhores imagens de um importante momento da história do Brasil, as dificuldades com as "fitas virgens para os registros", a "clandestinidade no trem até o Catete" e "as imagens feitas do capô do carro que conduziu Vargas pelas ruas curitibanas", esses relatos que não serão reproduzidos aqui com sua riqueza de detalhes, mas ficam como convite à leitura da presente dissertação.

A dissertação de Galigniana não produz uma análise interna dos filmes de João Baptista Groff, nem mesmo do documentário "João Baptista da Luz dos Pinhais". O autor deixa claro que essa abordagem não caberia no objetivo desenvolvido ao longo de seu trabalho e de sua pesquisa. O esforço acadêmico de Juan Cruz Galigniana apresenta muitas questões sugestivas e relevantes para pesquisa das memórias, das biografias, das identidades e da produção fílmica no Paraná e no Brasil. Contudo, o leitor não encontrará nesta dissertação uma análise fílmica da obra de João Baptista Groff, mas encontrará uma abordagem contextual sobre uma trajetória pública marcada pelas ações sociais e políticas de um período de construções de símbolos de identificação regional e nacional. 
Por fim, a dissertação intitulada "Construção social da memória em torno a João Baptista Groff e a ilusão biográfica" resulta de uma pesquisa que colocou em evidência os problemas nos processos de constituição da identidade e dos símbolos regionais. Ao encarar a trajetória de J. B. Groff e sua obra fílmica com um dos símbolos do "paranismo" presentes nas escolhas estéticas do fotógrafo e cine-documentarista, o autor Juan Cruz Galigniana discutiu de que maneira o que se conhece sobre os personagens e sua produção nos movimentos identitários compõem o repertório de uma imaginação social que pretende dar coerência aos relatos e as narrativas que embasam as memórias históricas e sociais. Deste modo, esta dissertação é uma contribuição para o campo da sociologia e das ciências humanas que tem como interesse investigar as trajetórias biográficas, nas complexidades que a temática suscita, ou seja, tomar como objeto de pesquisa a vida de uma personagem é um exercício que requer preocupações teóricas e metodológicas que ultrapassam o relato para fazer emergir as redes sociais, as relações de poder e o contexto de uma experiência na temporalidade. 